\title{
Potential Groundwater Extraction and Piezometric Surface Fluctuations in Puruliya, West Bengal - A GIS based study
}

\author{
Devarupa Gupta ${ }^{\mathrm{a}, *}$ \\ ${ }^{a}$ Ph. D. Research Scholar, International Institute for Population Sciences, Mumbai, India (email: \\ devarupagupta140890@gmail.com) \\ * Corresponding Author
}

Keywords: Groundwater, SRTM DEM, Puruliya, Lineament mapping

\begin{abstract}
:
A majority of Indians living in rural areas still primarily depend on agriculture for their sustenance. The water requirement is thus constantly high with groundwater being the most widely used source for domestic, agricultural and industrial use. More than $90 \%$ of the rural and nearly $30 \%$ of the urban populations depend on groundwater for meeting their drinking and domestic requirements causing an ever-rising demand for groundwater resources, resulting in an increase of the stress on these reservoirs and their consequent pollution. Water resources development occupies a key place in India because of its role in stabilizing the Indian agro-economy. Groundwater is a dynamic and replenishable natural resource but in hard rock terrain availability of groundwater is of limited extent.

This work attempts to present an overview of groundwater utilisation in the different blocks of Puruliya district, West Bengal and particularly within Puruliya Town (Municipality). Being a semi-arid district, Puruliya experiences hot and dry summers. Groundwater in the district occurs at shallow depths within the weathered mantle, fractural zones of hard rock, and narrow zones of unconsolidated sediments which are utilized by developing dug wells. During the peak of long and harsh summers, most of these openings dry out and there occurs a severe scarcity of water.
\end{abstract}

The objectives are:

- Block-wise assessment of groundwater fluctuation (recharge \& utilization), types of irrigation structures and present utilization status.

- To examine the groundwater abstraction and use in Puruliya town - the district headquarter.

- Remote sensing studies for locating weak zones and for understanding factors influencing groundwater movement in different geomorphologic setup.

- $\quad$ To highlight the problems associated with groundwater use and investigate possible solutions.

The following study is mostly done based on secondary data collected from various Central and State Government offices. The various data used and their sources are as follows:

1. District level groundwater reports from Central Groundwater Board, Eastern Region, Kolkata.

2. District and ward level administrative, land use and land cover, geomorphology and groundwater maps and statistics from Puruliya Town Municipality.

3. Shuttle Radar Topographic Mission Digital Elevation Model (SRTM DEM data for preparation of elevation and drainage maps along with Survey of India topographical maps (73E, 73I, 73J - R.F. - 1: 250, 000) for preparing several base maps.

4. Lineament extraction and mapping using SRTM DEM to show possible fracture zones that might be used for future groundwater abstraction.

5. Collating different reports together and preparing thematic maps to show the groundwater utilisation status of the different blocks in Puruliya district.

The work analyzes the correlations between the physiography, geomorphology, geology, hydrogeology, soils, climate and land use - land cover of the region with the groundwater zones. The present level of groundwater utilization in the district is mapped. Amount and quality of groundwater extracted, the levels of groundwater abstraction development block-wise are examined along with the different types of mechanical structures related to this. The nature of groundwater level fluctuation throughout the district at the Block level, in the Pre-Monsoon and Post-Monsoon season is also depicted and the long term terns of the peizometric surface behaviour analysed from these maps. The Block level utilisation as well the ward level utilisation of groundwater in the District Headquarter, Puruliya Town is mapped. A small attempt is also made to delineate some potential groundwater zones through lineament mapping and correlation with the earlier mapped variables. Problems faced in groundwater exploitation here and its ambient quality is also examined. 


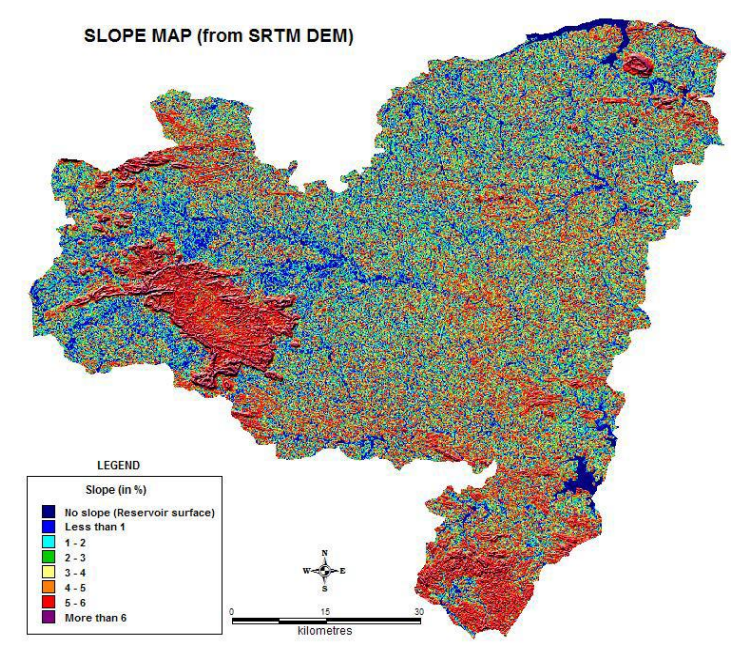

Figure 1. Slope Map from SRTM DEM of Puruliya district

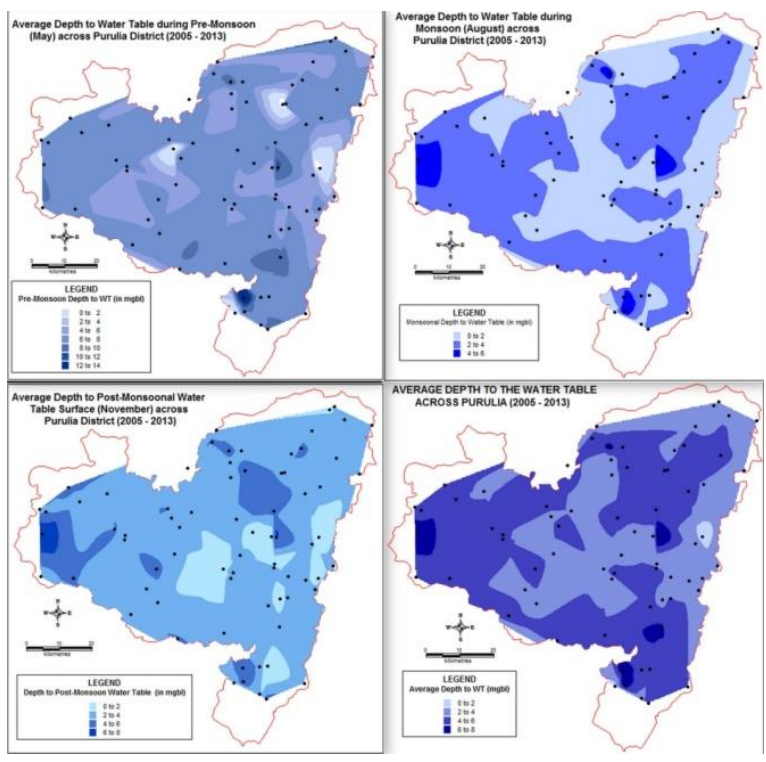

Figure 2. Average depth of water table in different seasons

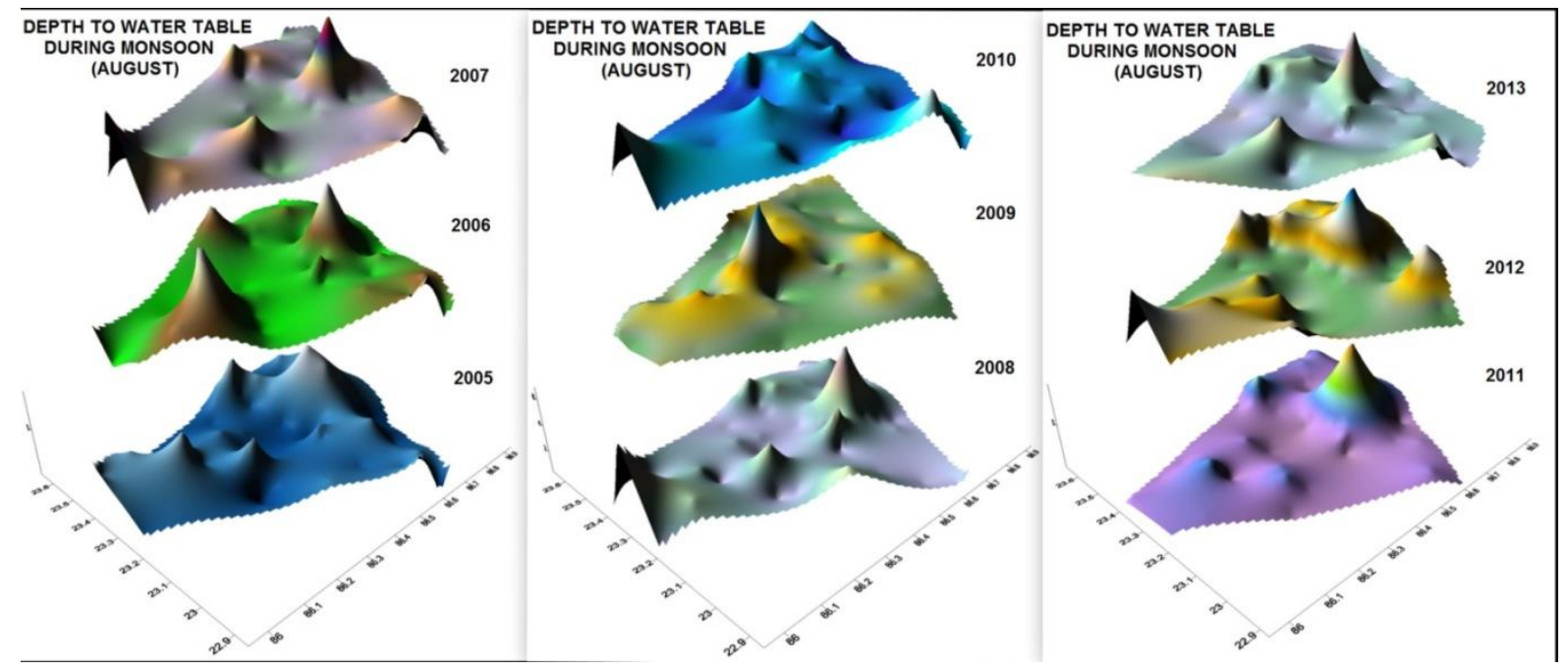

Figure 3. Average depth of water table in different years during the monsoon season

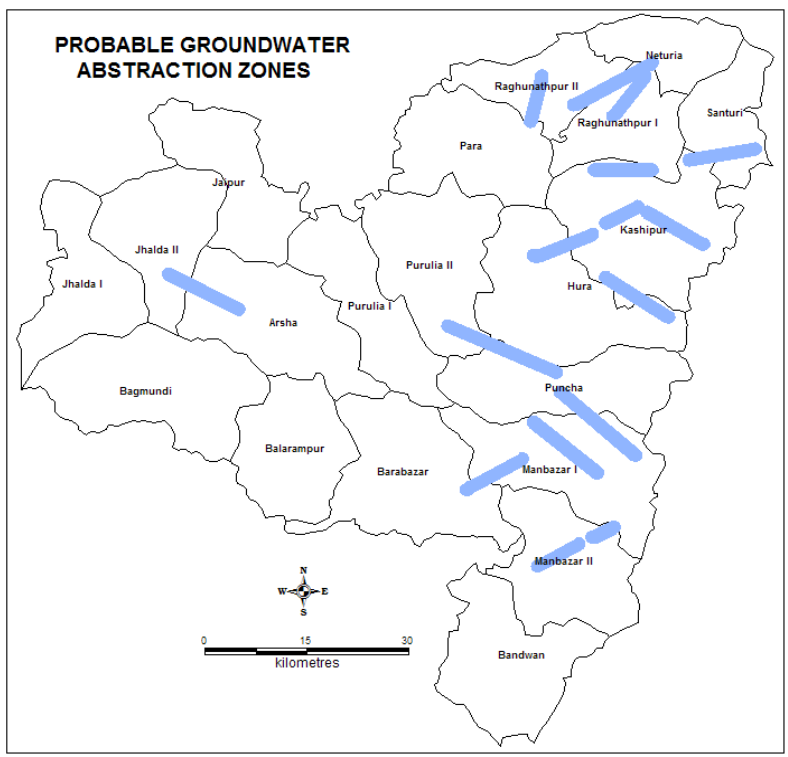

Figure 4. Probable Groundwater abstraction zones 